\title{
The role of information technology in enhancing the administrative capacity of the civil service: lessons from the USA
}

\section{Tesfaye Debela ${ }^{1}$}

\begin{abstract}
The New Public Management (NPM) model has inspired reforms both in the advanced as well as developing countries. However, due to the prevalence of a wide gap in administrative capacity, developing and advanced countries cannot have equal pace in implementing the NPM. The major objective of this paper is to demonstrate that the administrative capacity of a public organisation is a function of both high-level human resource capacity and the effective utilisation of Information Technology. In order to substantiate this, the paper elicited data from civil service employees in Ethiopia and USA, so that the gap analysis between the two countries can be discerned. In addition to this, the paper analyses the impact of IT on the trends of the civil service employees with different levels of capacities. The analysis led to two major findings. First, the increase in investment in IT had been negatively affecting the sizes of jobs that require low human resource capacity. Secondly, the increase in investment in IT had no impact on the size of jobs that require high-level of human resource capacity. Furthermore, the reduction in the size of the jobs that require lowlevel human resource capacity has an effect on the size of supervisors, which is the main proxy for measuring the hierarchical levels of an organisation. In conclusion, the experience of organisational change in developed countries such as USA can help developing countries to closely consider the dimension of information technology in the course of reforming their public service organisations.
\end{abstract}

\section{Introduction}

The concept of the New Public Management (NPM), with its emphasis on improving civil service delivery, alleviating the problem of budget deficits and measuring the performances of civil service organizations to make them accountable and responsible for their actions, has been preoccupying the minds of the politicians of western countries since the early 1980s. With regard to developing countries, the World Bank advises key ${ }^{1}$ Tesfaye Debela $(\mathrm{PhD})$ is currently an assistant professor in the Ethiopian Civil
Service College. 
decision makers to undertake civil service reforms that would contribute to improving their service delivery and control their budget deficits. One of the measures recommended for realising these objectives was reducing the redundant civil service staff. For example, beginning from 1992/93, Tanzania was required to lay off 50,000 of its civil servants out of the 330,000 in two and half years time (Malima, 1994). Ethiopia also reduced its civil service work force from 236,410 in 1989/90 to 223,733 in 1991/92, most likely, as a result of restructuring its civil service organisations (Federal Civil Service Agency, 2006: 18).

The extent of the practices of the NPM differs from country to country. For example, Borins (2000) noted that NPM had wider implication to UK than to USA because UK had to privatize its public enterprises side by side reforming its civil service organizations where as "the US has had relatively little public ownership since World War II". Although the concept of NPM includes a wide range of reform measures such as privatization of public enterprises, market testing and mechanisms introduced into the public sector, the discussion in this paper is limited to the civil service reform.

Governments rely on their civil service organisations to provide public services to their citizens. Hence, it is important to underline the main features of organizations so as to recognize the significance of information technology in improving the efficiency of the services of these public organizations. The definition of organization focuses around four features of organizations. These features are the collection of people, a purpose or common goal, a structure that shows a hierarchy of people and an information network (Narayan and Nath, 1993; Hax and Majluf, 1981). Information network serves as nervous system to organizations to monitor their internal and external situations so as to change their internal behavior in line with the changes in their operational environment. All types of organisations whether manufacturing or financial, government or nongovernment, - commonly have information networks to link their subsystems, to collect internal and external information, to report to the management subsystem, to pass instructions to units and to coordinate the activities of different specialised units of the organisation. 
Due chiefly to their socialist-oriented employment policy, most of the African states had overstaffed civil service. This paper argues that the source of inefficiency in civil service organisations of developing countries cannot only be attributed to overstaffing, but the weak administrative capacity emanating from shortage of qualified personnel and lack of capacity to use IT have also contributed to poor performance in the public service. Hence, both the availability of qualified personnel and investment in information technology determine the administrative capacities of the civil service organisations.

This paper comprises six sections. This section discusses the importance of high administrative capacity. The second section critically assesses the literature concerning the impact of IT on the efficiency of the activities of the civil service employees. The third section sets the hypotheses and develops the theoretical model for analysing the relationship between IT and human resource capacity. The size of white-collar workers is used as proxy measure of human resource capacity. ${ }^{1}$ The fourth section uses employee data from the US Federal Civil Service and analyses the data by differentiating the civil service jobs into high capacity and low capacity to explain the group of jobs that are affected as a result of investment in IT. The fifth section presents the results of the analysis. The last section demonstrates how the compositions of high-level and low-level white-collar workers have changed through time. Moreover, this section also draws some useful lessons with respect to the importance of IT in improving the efficiency of government service delivery and in changing the structure of the civil service organisations. More generally, the main contribution of this paper is the breaking of the civil service employees into major job categories to analyse the effect IT has on jobs that require high human resource capacity and low human resource capacity.

\section{Review of related literature}

One of the determinants of the size of an organisation is the number of people working in it. For decades, automation of physical activities has been affecting the productivity of organisations and the size of blue-collar workers. Similarly, since the mid 1960s, automation of information activities in offices has changed the nature of office work and has highly affected the 
activities of knowledge workers. Many scholars have discussed the contribution of IT in increasing the efficiency of organizations in collecting, classifying, documenting, storing and disseminating information; in making managerial decisions, in speeding communication and in improving capacities of organizational memory and knowledge (Pickering and King, 1995; Argyres, 1999; Henderson and Venkatraman, 1994). Groth (1999) and Rockart and DeLong (1988) discussed how IT has affected the size of organisations i.e., in reducing the hierarchies of an organisation and in reducing the size of white-collar workers.

On the other hand, there are also other authors who argue about the insignificant impact that IT has on reducing the size of whitecollar workers (Berndt et al, 1992; Suruga, 1991). The continuous investment in IT has resulted in an increase in the number of highly skilled white-collar workers (ibid). This implies that investment in IT has been complementing the tasks of high skilled white-collar workers.

Figure 1. IT Investment Per Capita in USA and EU

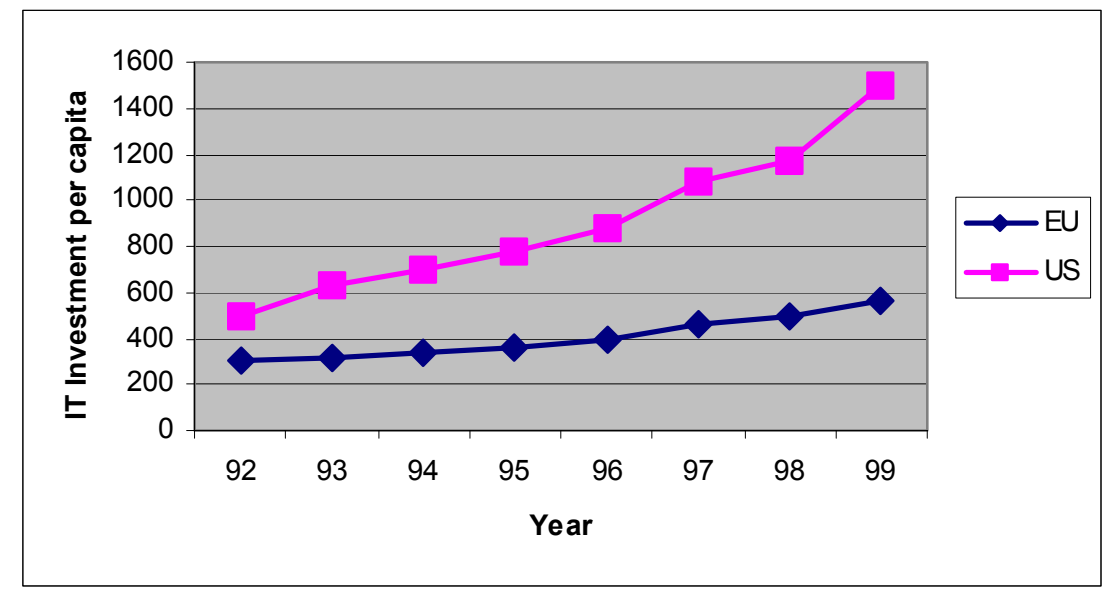

Source: European Tele-work Online, as adapted from EITO Reports, 1995-2001

In spite of the above arguments and counter arguments, expenditure on IT in US companies has grown from $\$ 80$ billion in 1984 to over $\$ 160$ billion in 1998 (Taylor, 1998). Moreover, Figure 1 illustrates that the per capita IT investments gap between USA and EU is increasing from time to time, and the cumulative ratio of IT investment by USA in EU had reached from 2.24 to 1 in 1999 (European IT Observatory, 1994-2001). 
The major question here is 'if IT doesn't increase productivity, then why do organisations rush to invest in it? ' This question can be dealt from two perspectives. The first is interms of organisations largely engaged in information processing activities, such as banks; and the second is with respect to organisations largely engaged in manufacturing activities such as automotive industries. The impact of IT on the two types of industries is different. In other words, IT affects more the efficiency of banking industry than it does the manufacturing industry.

In addition, we can make the following two assumptions as to why organisations rush into investing in IT from time to time.

1. Organisations have increased consumption of information due to the use of fast and efficient communication technology (Daft et al, 1990). This has led organisations to recruit qualified personnel that can effectively use IT to process data, to analyse problems and to make decisions.

2. Information Technology has enabled business organisations to operate at a global level. This global business operation has increased the volume of organisational activities, which led them to track and record abundant data for planning and decision. This can lead to the additional need of manpower in parallel to investing in information technology, and may conceal the effect of IT on the size of white-collar employment.

In general, there are three key reasons why it is difficult to measure the impact of IT on the efficiency of an organization visà-vis its expenditure on IT and the magnitude of profit that it generates. First, the expenditure on IT is not directly associated with the cost of the product. Second, the organization incurs additional cost to train employees and to adjust their salaries for the new skill acquired. Finally, the ability of business organizations to reduce their transaction costs as a result of the development of network technology has enabled customers to take price advantage.

As information technology (IT) is universally applicable to all types of organisations, it is important to assess the civil service 
reforms implemented in developing countries in light of the use of IT in enhancing the administrative capacity of government organisations. In this regard, a lot can be learnt from the civil service reform experience of the western countries. For example, USA and Canada promoted NPM through "integration of services, application of information technology, organizational redesign, and empowerment of workers and citizens" (Borins, 2000). Borins (ibid) further concluded that, among other things, it was the application of information technology that played "the critical role" in enhancing the public management reform programs in both USA and Canada.

The above discussion attests that due chiefly to enormous administrative capacity gap between developed and developing states, the pace of civil service reforms can be the same. Apparently, while public organizations in advanced countries are well equipped with highly qualified human resource capacity and information technology, their counter-parts in developing countries suffer from shortage of skilled manpower and inefficient use of information technology. Hence, developing countries, like Ethiopia, need to consider the realities that exist in advanced countries vis-à-vis their objective realities before they try to practice the solutions prescribed for the problems sought in the context of the advanced countries. Therefore, scholars in developing countries need to develop theoretical framework that support the efforts to implement the new public management by adapting the experiences of advanced countries to the realities of their home countries.

\section{The hypotheses and methodology}

\section{The hypotheses}

There have been many scholars who have tried to measure the efficiency of an organization through the contribution of IT. For example, Revenaugh and Philippakis (1994) used work-sampling method to measure productivity of IT based on before and after IT investment method. This implies that the efficiency of IT and its impact on organisational size can be determined in relation to the past performance achieved before the organisation used IT. Hence, the main point of departure for this analysis is the following statement noted from the writings of Motahashi (1997). 
While the share of employment directly related to IT is very small, the introduction of IT may also cause indirect changes in the occupation mix. ... That is the relative labour demand for high skilled, white collar workers involved in a complex and wide ranging duties using IT capital products, is becoming greater than that for blue -collar workers and low skilled white collar workers, who act as support staff for decision makers (ibid: 35 ).

According to Motahashi (1997), the change in occupation mix implies that the investment on IT has affected the size of organisations from two angles. First is that IT has caused the decrease in the size of lower level white-collar workers who are responsible for data gathering, recording and classification to support management decision or professional tasks. Second, IT has caused an increase in the size of professional and administrative workers who are responsible for systems and knowledge work in organisations. Therefore, using Motahashi's assumptions we can establish the following two hypotheses.

Hypothesis 1: Increase in IT capacity negatively correlates with the size of jobs that require low human resource capacity.

Hypothesis 2: Increase in IT capacity positively correlates with the size of jobs that require high human resource capacity.

\section{Methodology}

The main problem here is relating investments in IT, expressed in monetary terms, to the changes in the size of the civil service human resource capacity, expressed in quantity (numbers). We could have used the sum of the present values of the savings in salaries that would have been obtained from the replaced employees for the service years of IT less the present values of investment made in IT. However, there are two important points that we need to consider in analysing the relationships between human resource capacity and investment in information technology. The first is, unlike prices of products, the salaries or wages of civil service employees are subject to change in the quality of life and to changes in the economic growth of the 
country. The second is the price of information technology in relation to computer power is decreasing at exponential rate from time to time. Moreover, according to the reports of Congressional Budget Office (CBO, 2002), it is the "amount of memory", which is "one of the principal factors that federal agencies use in their quality adjustments of computer prices for statistical purposes". Based on the two points mentioned above, the model for the analysis is built first, by dividing the white collar workers into different categories; second, by determining the capacity of IT used in a specific work year; and third, by relating the capacity of IT and the size of white-collar workers per specific year.

\section{Operationalizing the hypotheses}

\section{The Variables for measuring the civil service human resource capacity}

In order to operationalize the above two hypotheses, we use the size of lower level white collar workers to measure the size of low human resource capacity and the size of high level white collar workers to measure the size of high human resource capacity. To simplify the complications, we can use the quotation from Motahashi to divide the total white-collar worker into higher level and lower level white-collar workers as follows:
$W_{t}=W h_{t}+W l_{t}$; Where $\boldsymbol{W}_{\boldsymbol{t}}$ is the number of total white collar workers at year $\boldsymbol{t}, \boldsymbol{W} \boldsymbol{h}_{\boldsymbol{t}}$ is the number of higher level white collar workers at year $\boldsymbol{t}$, and $\boldsymbol{W l _ { t }}$ is the number of low level white collar workers at year $\boldsymbol{t}$.

\section{The variable for measuring the capacity of IT}

The capacity of a computer is the function of its memory and its processing speed. Since both are correlated, it is possible to use either memory capacity or processing speed as a proxy measure for the capacity of a computer. 
Figure 2: Prices for dynamic random access memory, 1978-2000

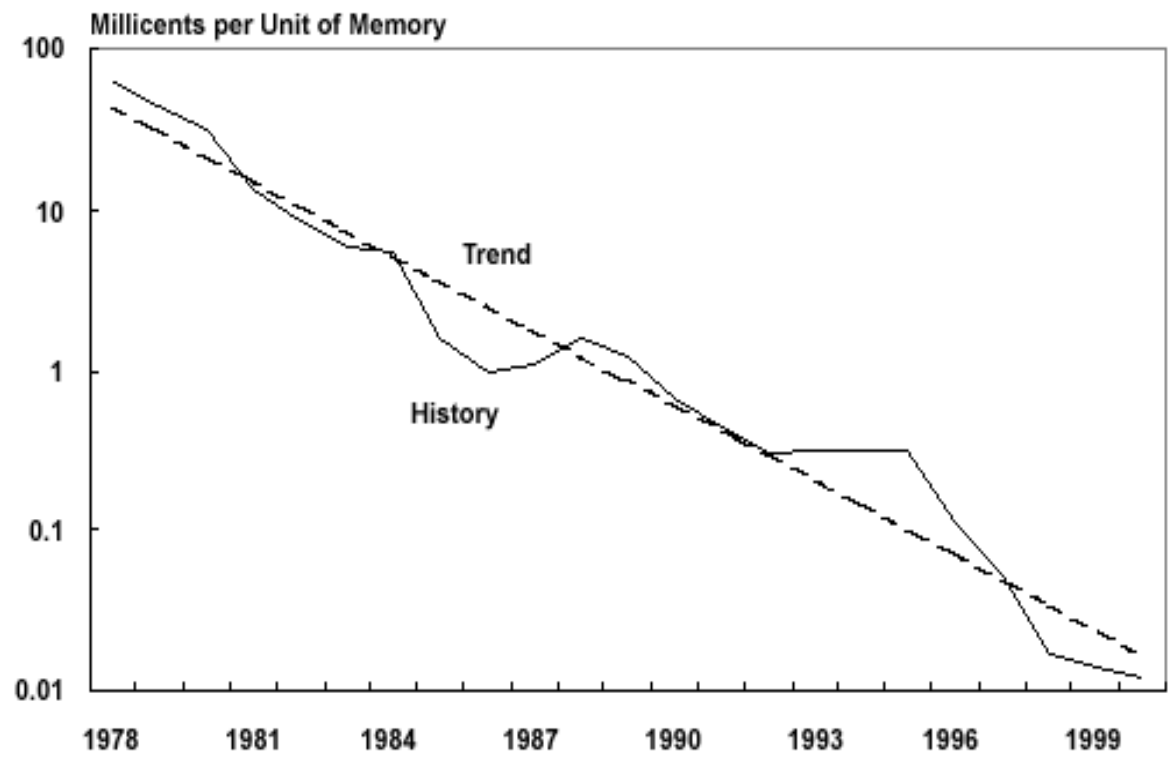

SOURCE: Congressional Budget Office (CBO) based on data from micron technologies and other industry sources ${ }^{2}$

Since it is easier for organisations to have records of the asset values of information technology than to have records of their computer capacities for each of their operational years, we can use the values of the assets of information technology that organisations have at a particular time to obtain the capacity of information technology involved in the provision of government service during the same year. Figure 2, taken from Congressional Budget Office (CBO) (2002), illustrates that the price of computers per unit memory is decreasing from time to time ${ }^{3}$. Figure 2 shows that there is negative linear relationship between the years (horizontal axis) and the logarithmic values of prices per unit memory (vertical axis). Hence, we can use this price per unit memory trend to convert the cumulative wealth of office equipment (as the proxy measure of the value of IT) into cumulative memory capacity of information technology at a specific period of year $\mathrm{t}$, which is symbolised as $C M_{t}$. (If interested, the reader can refer to Annex 1, Note 1 for the 
conversion of values of computers to memory capacity for a particular year).

\section{Establishing the relationship between the size of civil service employees and the capacity of IT}

From the simple economic theory of capital labour substitution, the marginal increase $\boldsymbol{M t}$ in the power of computers in year $\boldsymbol{t}$ causes a marginal decrease in the size of the white-collar workers of the following year. This assumes that labour is released from work immediately after the information technology becomes operational. Assuming a shift of capacity by one year to correspond the size of the white-collar workers of the following year doesn't make major difference in the outcome of this analysis, we can establish the following relationship between the capacity of computers and the size of white-collar workers applied for informational work performed in a particular year $t$.

$C M_{t} \Rightarrow W_{t}=W h_{t}+W l_{t} ; \boldsymbol{C M}_{\boldsymbol{t}}$ is the size of computer memory, $\boldsymbol{W}_{\boldsymbol{t}}$ is the size of the total civil service jobs at year $\boldsymbol{t}, \boldsymbol{W h}_{\boldsymbol{t}}$ is the size of jobs that require high human resource capacity at year $\boldsymbol{t}$ and $\boldsymbol{W l}_{\boldsymbol{t}}$ is the size of jobs that require low human resource capacity at year $t$.

\section{Source of data for analysis}

For our analysis, we have used the trend of the number of whitecollar employees of US Federal Civil Service between 1986 and 2000 , and the wealth value of office equipment ${ }^{4}$, of Federal Offices as a proxy measure of investment in information technology. The data for the size of civil service employees is collected from Personnel Statistics published by Ethiopian Federal Civil Service Agency and from different Federal Work Force Statistics of USA. The data for office wealth is taken from the Bureau of Economic Analysis (2000).

According to the job classification of the United States, there are 442 different white-collar occupations organized into 22 groups and classified into five major categories - namely: Professional, Administration, Technicians, Clerks and Others. The five categories are abbreviated as PATCO, representing the first letters of each of the five categories (US Office of Personnel Management, 1999: 178). The five categories are almost similar 
to the job classifications of the Ethiopian Federal Civil Service Commission.

The method used in this analysis is first to look at the trend of the total number of Federal Civil Service white-collar employees between 1986 and 2000 and then to divide this workforce into different categories to determine the category of the white-collar job that is more responsive to the investment in information technology.

Because of the difficulty of getting the data related to the number, memory, processing speed and investment values of computers that each federal department had acquired during the past years, the value of office equipments of the Federal Government, as taken from BEA, is converted into capacity of information technology. Therefore, the correlation between the capacity of information technology and the size of white-collar employees in the Federal Civil Services offices effectively measures the strength of the relationship between the two factors. The change in the hierarchies of organisations can also be measured using the change in the number of supervisors/managers, and the change in the organisation size can be measured using the change in the total number of civil servants working in Federal Civil Service Offices.

\section{Analysis}

It has been indicated earlier that there is a huge administrative capacity gaps between developing and developed countries. Two countries (namely, Ethiopia and the USA) that have remarkable differences in terms of possessing qualified personnel and use of information technology in their civil services are considered. Table 1 depicts the change of the number of federal civil service employees in Ethiopia and USA between 1991 and 2006, respectively. The data in the table shows the total number of civil service employees including the blue-collar workers and whitecollar workers in both countries. 
Table 1: Number of Federal Civil Service employees per one thousand people (For years 1991, 1999 and 2004)

\begin{tabular}{|l|r|r|l|l|l|l|}
\hline & \multicolumn{3}{|c|}{ Ethiopia } & \multicolumn{3}{c|}{ USA } \\
\cline { 2 - 7 } & Population & $\begin{array}{l}\text { No of } \\
\text { Employees }\end{array}$ & $\begin{array}{l}\text { No. of } \\
\text { Employees } \\
1000 \text { people }\end{array}$ & Population & $\begin{array}{l}\text { No of } \\
\text { Employees } \\
\text { (CS) }\end{array}$ & $\begin{array}{l}\text { No. Of CS } \\
1000 \\
\text { people }\end{array}$ \\
\hline 1991 & 49150000 & $0^{5}$ & 0 & $252660000^{*}$ & $3120000^{* *}$ & 12 \\
\hline 1999 & 63493000 & 41930 & 1 & $273000000^{*}$ & $2748800^{* *}$ & 10 \\
\hline $\begin{array}{l}2006 \\
\text { (Ethiopia)/20 } \\
\text { 04 (USA) }\end{array}$ & 75067000 & 52833 & 1 & 293102000 & 2713200 & 9 \\
\hline
\end{tabular}

Source: Annual Statistics of the Federal Civil Service Commission of Ethiopia (2000 and 2006); Ethiopian Statistical Agency (2006) *US Census Bureau, 2000 and 2008; ** US Office of Personnel Management (2000 and 2004)

Ethiopia had nearly 223,700 civil service employees in 1991/92. During this period, since Ethiopia was in the process of establishing itself as a federal state, the country was not considered as having federal civil service employees.. In Ethiopia, the ratio of the federal civil service employees per 1000 people increased from zero in 1991 to one in 1999, and it remained the same until 2006. For USA, the ratio of the Federal Civil Service employees per one thousand people had decreased from twelve in 1991 to ten in 1999, and further decreased to nine in 2004. This shows that developing countries are suffering not only from poor quality but also from insufficient quantity of manpower. While the populations in both countries had increased, the decrease in the proportion of the federal civil service employees of USA per 1000 people prompts one to critically question why this reversal had taken place and to identify which job category had been extremely affected as a result of investment in IT. 
Figure 3. Trend of total Federal white-collar workers of USA between 1986-2000

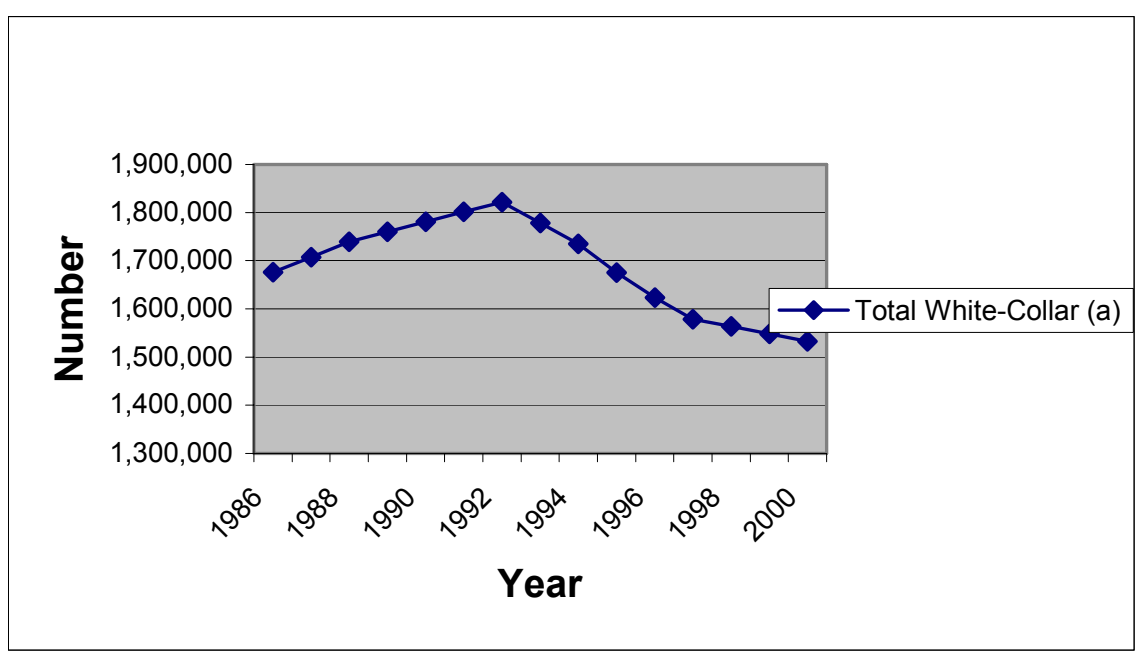

Source: Charted from the Fact Book of the 2001 edition

Figure 3 illustrates that the number of white-collar Federal civil service employees of USA has increased from 1,675,000 in 1986 to 1825000 in 1991; and later, declined to 1525000 in 2000.

This shows that there was an average increase of $1.8 \%$ per year (a total increase of 9\%) between 1986 and 1991; and an average decline of $1.8 \%$ per year (a total decline of 16.4\%) between 1991 and 2000. In order to identify the job categories that have been affected by the increase in the use of information technology, we break the total number of white-collar employees shown in Figure 3 into the five job categories, as mentioned in the methodology part. We then evaluate the trends of each category of white-collar workers in Figure 4 (see Annex 2 for data sources). 
Figure 4. Trends of white-collar employees by category: 19881999

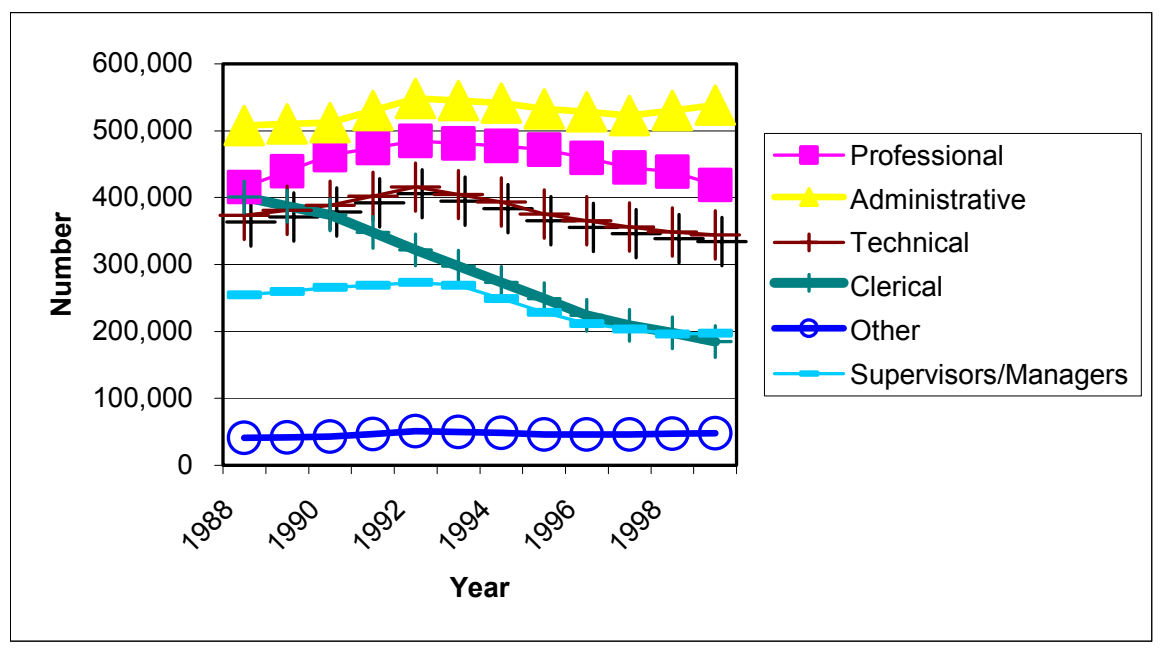

Source: US Office of Personnel Management, Federal civilian workforce statistics

As shown in Figure 4, the number of clerks had been decreasing while the number of supervisors, professionals, and administrative and technical staff had been relatively increasing between 1986 and 1991 in the US. The administrative staff category includes computer specialists and the technical category includes the accounting technicians. Between 1988 and 2000, the size of computer specialists had increased by $24 \%$ where as the size of accounting technicians had decreased by $36 \%$ (US Office of Personnel Management, 2000). The movements of the two jobs in opposite directions purports that Federal Civil Service Organisations have been employing more computer specialists while reducing the size of accounting technicians as they automate their accounting systems.

\section{Results}

The next step is to test the two hypotheses for the causes of drastic declines in the sizes of clerks, supervisors and accounting technicians. Using the wealth in office equipment as a proxy measure for the asset value of information technology, and converting this asset value of information technology into capacity of information technology using the price model found 
on page eight, we get the correlation results for:

1. the relationships between the capacity of computer technology employed and the size of each category of white-collar workers;

2. the relationships between the numbers of any two different categories of white-collar workers for the period between 1988 and 1999.

Table 2: Correlations analysis of different categories of white-collar workers and capacity of IT (data for 12 years between 1988 and 1999)

\begin{tabular}{|c|c|c|c|c|c|c|c|}
\hline & $\begin{array}{c}\text { Total } \\
\text { White-Collar }\end{array}$ & Professional & Administrative & Technical & Clerical & Other & $\begin{array}{c}\text { Supervisor/ } \\
\text { Managers }\end{array}$ \\
\hline $\begin{array}{l}\text { IT Capacity in } \\
\text { Memory Units }\end{array}$ & $\begin{array}{r}-0.7054 \\
\left(0.000^{* *}\right)\end{array}$ & $\begin{array}{l}0.1347 \\
(0.126)\end{array}$ & $\begin{array}{l}0.6324 \\
(0.106)\end{array}$ & $\begin{array}{r}-0.4424 \\
\left(0.006^{* *}\right)\end{array}$ & $\begin{array}{r}-0.9674 \\
(0.000 * \\
*)\end{array}$ & $\begin{array}{l}0.6713 \\
(0.104)\end{array}$ & $\begin{array}{r}-0.7259 \\
\left(0.001^{* *}\right)\end{array}$ \\
\hline $\begin{array}{l}\text { Total white- } \\
\text { collar empl. }\end{array}$ & & $\begin{array}{r}0.5782 \\
\left(0.049^{*}\right)\end{array}$ & $\begin{array}{r}-0.0058 \\
(0.986)\end{array}$ & $\begin{array}{r}0.9425 \\
(0.000 * *)\end{array}$ & $\begin{array}{r}0.8489 \\
(0.000 * \\
*)\end{array}$ & $\begin{array}{r}-0.0585 \\
(0.857)\end{array}$ & $\begin{array}{r}0.9919 \\
\left(0.000^{* *}\right)\end{array}$ \\
\hline Professional & & & $\begin{array}{r}0.5765 \\
(0.050) \\
\end{array}$ & $\begin{array}{r}0.7782 \\
(0.003 * *) \\
\end{array}$ & $\begin{array}{r}0.0905 \\
(0.780) \\
\end{array}$ & $\begin{array}{r}0.5734 \\
(0.051) \\
\end{array}$ & $\begin{array}{r}0.5201 \\
(0.083) \\
\end{array}$ \\
\hline Administrative & & & & $\begin{array}{r}0.3063 \\
(0.333) \\
\end{array}$ & $\begin{array}{r}-0.4905 \\
(0.105)\end{array}$ & $\begin{array}{r}0.9812 \\
\left(0.000^{* *}\right)\end{array}$ & $\begin{array}{r}-0.0203 \\
(0.950) \\
\end{array}$ \\
\hline Technical & & & & & $\begin{array}{r}0.6277 \\
(0.029 *) \\
\end{array}$ & $\begin{array}{r}0.2642 \\
(0.407) \\
\end{array}$ & $\begin{array}{r}0.9234 \\
\left(0.000^{* *}\right) \\
\end{array}$ \\
\hline Clerical & & & & & & $\begin{array}{r}-0.5432 \\
(0.068) \\
\end{array}$ & $\begin{array}{r}0.8652 \\
\left(0.000^{* *}\right) \\
\end{array}$ \\
\hline Other & & & & & & & $\begin{array}{r}-0.0783 \\
(0.809) \\
\end{array}$ \\
\hline
\end{tabular}

Source: Computed by the author from the data source presented in annex 2.

Level of significance for one tail Student's t test: $p^{* *<0.01, p^{*}<0.05}$ (Numbers without brackets are correlation values and numbers within brackets are $\boldsymbol{p}$ values)

The significance of the negative correlation between the capacity of computers and the total number of white-collar workers $(p<0.01)$ implies that the decrease in the total size of white-collar workers is related to the increase in the capacity of information technology in the Federal Civil Service. However, this negative relationship between the gross size of white-collar employees and the capacity of information technology conceals vital information about the group of white-collar workers that can extremely be affected by the investment in information technology. 
Breaking the total civil service employees into major categories of white-collar provides the correlation results in the above table that can divide the groups into two. The first group contains the categories of professionals, administrative staff and others for which their respective sizes are positively correlated to, but not significantly affected by, the increase in the power of information technology (all respective p-values $>10 \%$ ). The second group contains the categories of clerks and technicians for which the respective sizes are significantly being affected by the increase in the capacity of information technology. The increase in the capacity of information technology negatively correlates with the trend of the number of clerks (significant at $p<1 \%$ ) and with the number of technicians (significant at $p<1 \%$ ) respectively.

Further analysis of Table 2 provides ample evidence about the impact of information technology on the hierarchical change of organisations. The first evidence is the strong negative correlation between the increase in the capacity of information technology and the number of supervisors (significant at $p<1 \%$ ). This significant negative correlation purports that investment in IT has been the major factor in reducing the levels of organisational hierarchies. The second evidence is the strong positive correlations between clerks and supervisors $(p<0.001)$; technicians and clerks $(p<0.03)$; and technicians and supervisors $(p<0.001)$. This implies that the more the decrease in the size of jobs that require low capacity human resource as the result of investment in information technology, the more the decrease in the size of supervisors and the more the decrease in the hierarchy of an organisation.

Therefore, the application of information technology to automate the operational routine tasks of Federal Civil Service organisations has been the major factor for the changes in the structure of white-collar employees of the Federal Civil Service of USA between the year 1992 and the year 2000 .

\section{Discussion}

During the 1990s, investment in IT has been the major factor in substantially reducing the number of white-collar workers. The insignificant positive correlations between the increase in the capacity of information technology and the sizes of the high capacity civil service employees (professionals, administrative 
staff and others) and the significant negative correlations between the capacity of information technology and the lower level white collar workers (technicians and clerks) substantiate the assumption of Motohashi (1997) in two major respects. The first is that the investment in IT has not affected the demand for highskilled white-collar workers doing a variety of duties using IT. The second is that investment in IT has affected the change in the occupation mix of employees as evidenced by a positive correlation between investment in IT and the other categories of civil service employees ( $p \cong 0.1$ ).

Figure 5: Comparison of percentage of each category of civil service employees between Ethiopia and USA

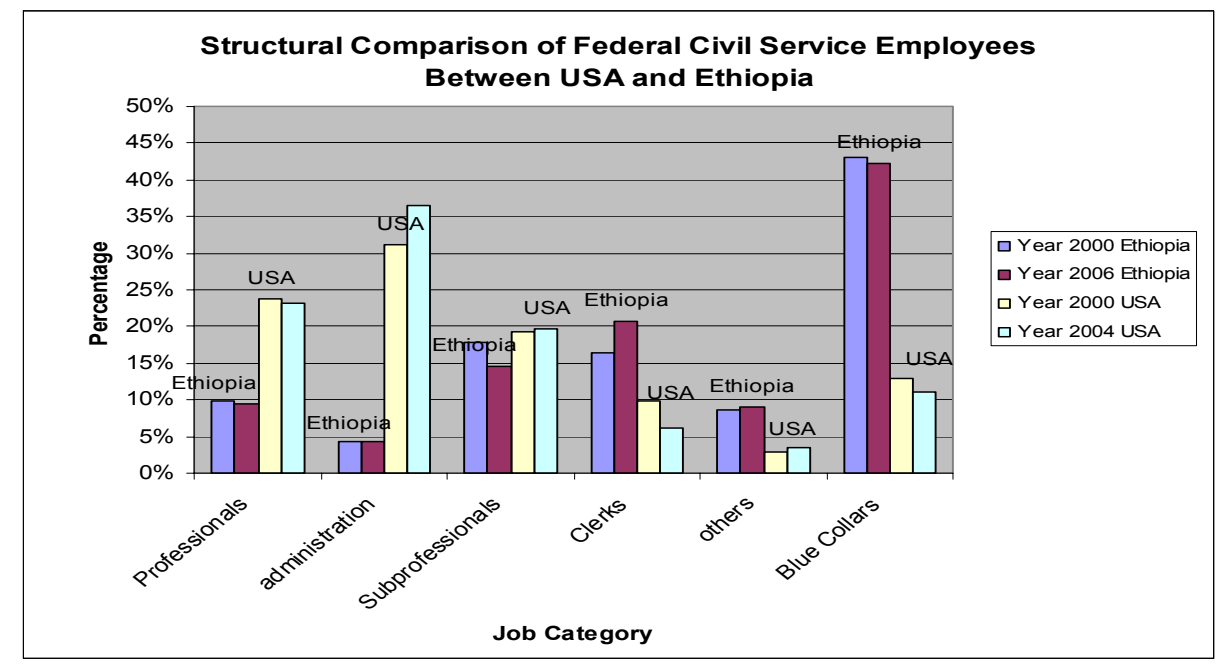

Sources: Charted from the annual statistics of the Federal Civil Service Commission of Ethiopia (2000 and 2006); US Office of Personnel Management, Factbook, (2000 and 2005)

By reducing the levels of hierarchies, IT has enabled the administrative staffs and the professionals to incorporate the routine tasks performed at operational level to their major complex professional tasks. This signifies the possibility of vertically integrating the lower level tasks to higher-level tasks. The non-significant relationship between the increase in the capacity of information technology and the change in the size of professional employees indicates the importance of IT in supporting the high level professional tasks. The non-significant positive correlation between the increase in the number of 
administrative staff and the increase in the investment of information technology substantiates the complementarities of administrative staff and their using of computers in offices. For example, it is possible for a professional or administrator to encode his data to the computer rather than waiting for a clerk or secretary to type his draft writing.

Our main focus here is on developing a path model for developing countries like Ethiopia, so that they can adjust their pace by finding the optimum mix of investment in information technology and creating high capacity human resource in their effort of implementing the NPM. To deal with this issue, Figure 5 helps to contrast the percentage ${ }^{6}$ of each category of federal employees between the Federal Civil Service of Ethiopia and the Federal Civil Service of USA by taking the 2006 data of year as example. For Ethiopia, the percentage of professionals, administrative staff $^{7}$, sub professionals, clerks, others and blue collar workers are $10 \%, 5 \%, 15 \%, 20 \%$ and $50 \%$ respectively (see Figure 5). For USA, the percentages of professionals, administrative staff, sub professionals, clerks, others and blue collar workers are $23 \%$, $36 \%, 20 \%, 5 \%, 3 \%$ and $10 \%$ respectively. One can therefore deduce that while the structure of the Civil Service of Ethiopia is highly inclined towards having low capacity employees, the structure of the civil service of USA is highly inclined towards high capacity employees. One important point to note from Figure 5 is that the structure of the Ethiopian civil service had not been changed for the seven years period between 1999 and 2006. In other words, the weights of jobs that require low human resource capacity, such as clerks and blue-collar workers, are much higher than the jobs that require high human resource capacity, such as professionals and administrative staffs.

Figure 5 also conveys valuable information on the wide gap of administrative capacity between the federal civil service employees of the two countries. Connecting the two extreme points helps to draw the trend of the categories of civil service employees through time as shown in Figure 6. To illustrate the nature of progress from low administrative capacity to high administrative capacity of the civil service, Figure 6 divides the total civil service employees into two major groups - clerks, representing the low capacity human resource; and professional and administration staffs, representing the high capacity human 
resource. The diagram illustrates the direction of the strengthening of the administrative capacity of the civil service as one moves from Box $\mathbf{C}$ to Box B. As more investment is made in information technology, the strategy should focus on enhancing the human resource capacity so as a civil service organization can move towards Box B. If more emphasis is given to investment in IT than enhancing the human resource capacity, the organization is moving towards box $\boldsymbol{D}$ where the organization experiences wastage of IT resources rather than improving its service efficiency. If a civil service organization is found at Box $A$, it should follow the strategy of enhancing the use of IT so as to be transformed to high administrative capacity found at Box B. Box $\boldsymbol{C}$ reflects the current status of Ethiopia whereas box $\boldsymbol{B}$ reflects the current status of the Federal Civil Service of USA. Box $\boldsymbol{B}$ represents high civil service administrative capacity which is the result of high human resource capacity and high capacity of IT that Ethiopia aspires to attain in the future.

Figure 6: The transformation path from low administrative capacity to high administrative capacity

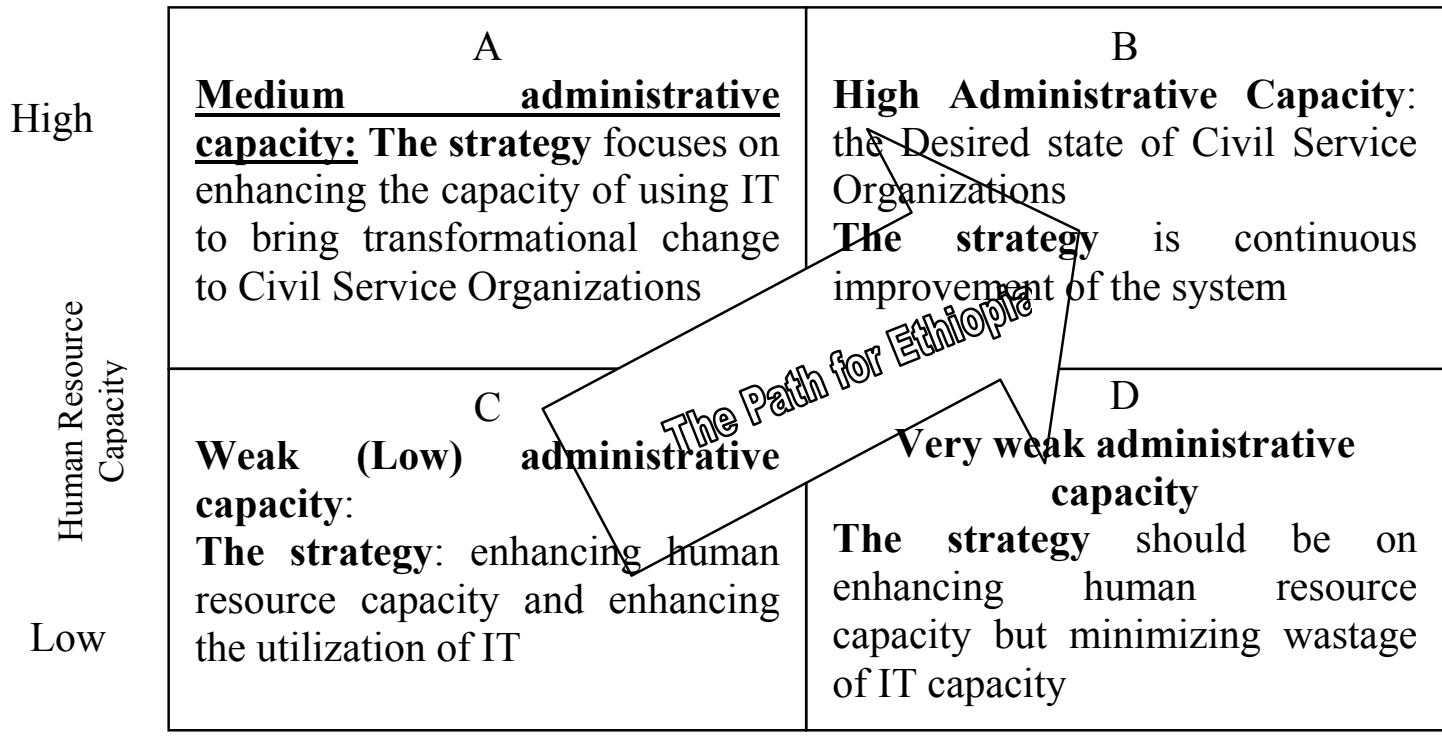

Low

Capacity of information

High

Source: Own model 


\section{Conclusion}

This analysis has an implication for developing countries including Ethiopia, which are undertaking civil service reforms to increase efficiency of the public service delivery. As noted earlier, administrative capacity is a function of highly qualified civil service employees and effective utilisation of information technology. In order to have an efficient and effective administrative system, developing countries need to invest more in information technology and to increase the number and quality of high-capacity employees who can use IT for a wide variety of administrative and professional tasks.

It is true that governments in developing countries may have fears that an investment in IT would result in high unemployment rate. However, taking the Ethiopian case as frame of reference, unemployment is not the main issue as long as the current available federal civil service employees should have been nine times of the civil service employees actually employed today (see Table 1). Therefore, in the short run, the main reasons for weak administrative capacities of civil service organisations in developing countries are the high investment required for information technology, the high training need of manpower and the lack of vision as to how to use the available information technology to the strategic advantages of civil service organisations. Hence, organisation specialists in developing countries need to take these problems into account when they consider different strategies to improve the operational processes of civil service organisations.

To conclude, I would like to remind readers to take Figure 6 as a point of departure. If Ethiopia has to attain the level development that the US Federal Civil Service has achieved today, this can be done in twenty years from now provided that other factors (economic, social, political and technological factors) remain favourable. Additionally, ample opportunity should be opened for the Ethiopian public organisations to learn from civil service organisations of advanced countries. Hence, researchers in the area should exert more effort to find plausible models that suggest the optimal mix of investment in information technology and the different categories of the civil service jobs. 


\section{Annex 1 Notes}

Note 1: the Conversion of price per unit-memory to memory capacity of IT

From Figure 2, we can deduce the following exponential equation that consists of the Millicent per unit memory $\left(\boldsymbol{p}_{\boldsymbol{t}}\right)$, as dependent variable, and time period $t$, as independent variable.

$$
\begin{array}{r}
p_{t}=10^{\left(-0.153866^{t+1.6923)}\right.} \text {; where } \boldsymbol{p}_{\boldsymbol{t}} \text { is the Millicent per unit } \\
\text { memory at time } \boldsymbol{t} \text { and } \boldsymbol{t} \text { is the number of } \\
\text { years starting from the year } 1978 \text {. }
\end{array}
$$

After obtaining the price memory relationship, we need to separate the net asset of information technology of year $\boldsymbol{t}$ into net assets of information technology transferred from the previous year (t-1) and the additional investment made in information technology in year $\boldsymbol{t}$. Hence, the following four steps are used to find the cumulative capacity of information technology of year $\boldsymbol{t}$.

1. Divide the wealth value in IT of the starting year to the price per unit memory of the starting year to obtain the starting capacity of information technology $\left(\mathbf{C m}_{1986}\right)$

2. obtain the marginal wealth $(\mathbf{A m})$ of IT increased for each year after the year 1986 .

3. divide the marginal investment of information technology $(A m)$ in year $t$ to the price per unit memory of year $t$, obtained from the above price per unit memory formula. This is expressed using the following relationship and yields the information technology capacity added in year $\mathbf{t}$.

$$
\begin{array}{r}
M_{t}=\frac{A m_{t}}{P_{t}}=A m_{t} P_{t}^{-1} \begin{array}{l}
\text { where } M_{t} \text { is additional } \\
\text { information technology memory } \\
\text { capacity added in year } t, \boldsymbol{A m}_{\boldsymbol{t}} \text { is }
\end{array} \\
\text { the increase in the wealth of information } \\
\text { technology in year } \boldsymbol{t} \text { and } \boldsymbol{P}_{\boldsymbol{t}} \text { is the Millicent } \\
\text { per unit memory of computer at year } t .
\end{array}
$$

4. Add the marginal information technology capacity $\left(\boldsymbol{M}_{t}\right)$ you obtained in step three to the total capacity of IT of the previous year to obtain the cumulative capacity of information technology $(\boldsymbol{C M})$ for year $\boldsymbol{t}$. 
$C M_{t}=C M_{t-1}+M_{t}$; where $\boldsymbol{C} \boldsymbol{M}_{t}$ is the cumulative capacity of information technology involved in information processing work in year $t ; \quad \boldsymbol{C M}_{t-1}$ is the cumulative capacity of information technology transferred from the year $\boldsymbol{t}-\mathbf{1}$; and $\boldsymbol{M}_{\boldsymbol{t}}$ is the capacity of information technology added in year $t$. 
Annex 2 Trend of Wealth in Office Equipment and White Collar Workers between 1988 and 1999

\begin{tabular}{|c|c|c|c|c|c|c|c|c|c|c|c|c|}
\hline Year & Time $\mathbf{t}$ & $\begin{array}{c}\text { Wealth in } \\
\text { Office } \\
\text { Equmt } \\
\left(A_{t}\right)\end{array}$ & $\begin{array}{c}\text { Margina } \\
\text { I Wealth } \\
\text { (Am) }\end{array}$ & $\begin{array}{l}\text { Millicent } \\
\text { per unit } \\
\text { memory }\end{array}$ & $\begin{array}{l}\text { Capacity } \\
\text { (in } \\
\text { memory } \\
\text { units) }\end{array}$ & $\begin{array}{c}\text { Total } \\
\text { White- } \\
\text { Collar (a) }\end{array}$ & $\begin{array}{c}\text { Profession } \\
\text { al }\end{array}$ & $\begin{array}{c}\text { Administr } \\
\text { ative }\end{array}$ & $\begin{array}{c}\text { Technic } \\
\text { al }\end{array}$ & Clerical & Other & $\begin{array}{c}\text { Supervis } \\
\text { ors/Mana } \\
\text { gers }\end{array}$ \\
\hline 1988 & 11 & 485 & & 1.001 & 48444.19 & $1,738,911$ & 415,545 & 508,063 & 373,294 & 401047 & 40962 & 254474.8 \\
\hline 1989 & 12 & 517 & 32 & 0.703 & 52998.79 & $1,759,893$ & 439,561 & 510,134 & 380,914 & 387408 & 41877 & 259691.5 \\
\hline 1990 & 13 & 559 & 42 & 0.493 & 61517.02 & $1,780,874$ & 463,576 & 512,204 & 388,534 & 373768 & 42792 & 266058.3 \\
\hline 1991 & 14 & 592 & 33 & 0.346 & 71054.07 & $1,801,295$ & 474,071 & 530,301 & 402,209 & 347921 & 46794 & 269109.1 \\
\hline 1992 & 15 & 608 & 16 & 0.243 & 77643.07 & $1,821,715$ & 484,566 & 548,397 & 415,883 & 322073 & 50796 & 273257.3 \\
\hline 1993 & 16 & 645 & 37 & 0.170 & 99355.17 & $1,778,194^{*}$ & $481,088^{*}$ & $545,064^{*}$ & $404,561^{*}$ & $297717^{*}$ & $49765^{*}$ & 268846 \\
\hline 1994 & 17 & 672 & 27 & 0.120 & 121932.04 & 1734673 & 477610 & 541731 & 393239 & 273360 & 48733 & 248976.6 \\
\hline 1995 & 18 & 686 & 14 & 0.084 & 138613.27 & 1675075 & 471694 & 532557 & 375493 & 249161 & 46170 & 228598.5 \\
\hline 1996 & 19 & 692 & 6 & 0.059 & 148800.39 & 1623205 & 459121 & 528238 & 365449 & 224040 & 46357 & 211394.1 \\
\hline 1997 & 20 & 694 & 2 & 0.041 & 153639.10 & 1578576 & 444721 & 522698 & 355919 & 209278 & 45960 & 203746.4 \\
\hline 1998 & 21 & 698 & 4 & 0.029 & 167428.96 & 1563644 & 439041 & 530192 & 348720 & 198222 & 47469 & 195904.8 \\
\hline 1999 & 22 & 727 & 29 & 0.020 & 309890.62 & 1534643 & 419057 & 538350 & 344152 & 185121 & 47963 & 197511.6 \\
\hline
\end{tabular}

Source: For the employee statistics, US Office of Personnel Management FEDERAL CIVILIAN WORKFORCE STATISTICS, The Fact Book 1997, 1998,

1999, 2000, and 2001 EDITION; Bureau of Economic Analysis (2000), for wealth in office equipment data. 
Notes

${ }^{1}$ White-collar worker: pertaining to or designating professional or clerical workers whose jobs are usually salaried and do not involve manual labour. Blue-collar worker: pertaining to or designating factory workers, manual labourers, or the like, who usually wear work clothes and earn weekly wages.

${ }^{2}$ The figure uses a logarithmic scale in the price axis. The prices at the beginning of the period are so much higher than those at the end--by close to five orders of magnitude--that presenting the same information using an arithmetic scale would obscure most of the interesting phenomena after 1987 (CBO, 2002).

${ }^{3}$ The price per memory of year $t$ and the memory capacity is included in the table of annex 2 .

${ }^{4}$ Wealth is taken as the net values of equipments used in a particular year. (Net value $=$ Total Value less depreciation

${ }^{5}$ This indicates only the number of federal civil service employees but does not mean that there were no civil servants in Ethiopia in 1991. In 1991/92, the number of civil servants at national level was 223,733.

${ }^{6}$ Percentage is calculated by dividing a single category of civil service employees to the total number of civil service of a country.

${ }^{7}$ According to the Federal Civil Service Commission of Ethiopia, all degree holders are considered as professionals. Therefore the reader should note that the number of administrative staff, taken from the statistical data of the FCSC is adjusted to reflect the actual number working in administration. 


\section{References}

Argyres, N. S. 1999. The Impact of Information Technology on Coordination: Evidence from the B-2 "stealth" bomber. Organization Science, 10 (2): 162-180.

Berndt, E., Morrison C., Rosenblum L. 1992. High Tech Capital, Economic and Labour Composition in US manufacturing Industries: An Explanatory Analysis. NBER Working Paper Series. Vol. 10. Cambridge, MA.

Borins, S. 2000. New Public Management: North American Style, in McLaughin, Kate, Osborne, Stephen P. and Ferlie, Ewan, eds. New Public Management: Current Trends and Future Prospects. UK. Routledge Publishers: Taylor and Francis Group, pp. 181-194.

CBO 2002. The Role of Computer Technology in the Growth of Productivity. Available at https: $/ /$ www.cbo.gov/doc.cfm?index $=3448 \&$ type $=0 \&$ sequence $=4$

Central Statistical Agency of Ethiopia 2006. The 2005 National Statistics. Available at http://www.csa.gov.et/text_files/national\%20statistics\%202005/Population.pdf

Daft, R. L., Kenneth R. Bettenhausen, and Beverly B. Tyler 1993. Implications of Top Managers Communication Choices for Strategic Decisions. In Huber, P. and Glick, William H.(Eds), Organizational change and Redesign. New York. Oxford University Press.

Ethiopian Federal Civil Service Commission 2001. Personnel Statistics, Addis Ababa, Ethiopia. 2006. Personnel Statistics, Addis Ababa, Ethiopia

Groth, L. 1999. Future Organizational Design. New York. John Wiley and Sons.

Hax, A. C. and Majluf, N. S 1981. Organisation Design. In Paul Mali (Eds), Handbook of Management Operating Guidelines, Techniques and Practice. New York: A Ronald Press Publication.

Henderson, J. C., Venkatraman, N. 1994. Strategic alignment: a model for organizational transformation via information technology. In. Allen, T. J and Morton, S. (Eds.). Information technology and the corporation of the 1990s. New York: Oxford University Press.

Malima, K. 1994. Structural Adjustment: The African Experience, Key Note Address. In Van der Hoeven. R. and van der Kraaij, F. (Eds). Structural Adjustment and Beyond - Proceedings of an International Seminar on Structural Adjustment and 
Long-Term Development in Sub-Saharan Africa: Research and Policy Issues: London: James Curry Publishers.

Motohashi, K. 1997. ICT Diffusion and Its Economic Impact in OECD Countries. Science, Technology and Industry Review, No. 20. Paris: OECD

Narayan, V.K., Nath, R. 1993. Organisation Theory. Homewood: Richard D. Irwin.

Pickering, J. M, King, J. L. 1995. Hardwiring weak ties: inter-organizational computermediated communication, occupational communities, and organizational change. Organization Science, 6 (4): 479-486.

Rockart, J., DeLong, D. 1988. Executive Support Systems: the Emergence of Top Management Computer Use. Burr Ridge, IL: Dow-Jones-Irwin.

Taylor, G. H. 1998. Knowledge Companies. In Halal, W. E. (Eds.). The Infinite Resource: Creating and Leading the Knowledge Enterprise. San Francisco: Richard D. Irwin.

U.S. Census Bureau 2000. Statistical Abstract of the United States. Available at http://www.census.gov/prod/cen2000/phc3-us-pt1.pdf

2008. Statistical Abstract of the United States. Available at http://www.census.gov/popest/topics/methodology

US Office of Personnel Management 1999. Federal Civilian Work Force Statistics, Occupations of Federal White-Collar and Blue Collar Workers. Washington DC, USA.

1997. Federal Civilian Workforce Statistics, The Fact Book 1997 Edition Washington DC, USA,

1998. Federal Civilian Workforce Statistics. The Fact Book 1998 Edition Washington DC, USA.

2001. Federal Civilian Workforce Statistics, The Fact Book 2001 Edition Washington DC, USA.

1997. Occupation of Federal White-Collar and Blue Collar Workers. Washington DC, USA.

1999. Occupation of Federal White-Collar and Blue Collar Workers. Washington DC, USA.

US Office of Personnel Management 2000. Federal Civilian Work Force Statistics. 
Washington DC, USA.

Revenaugh, L., Philippakis, A. S. 1994. White-Collar Productivity and the Effect of Information Technology: Can it be Measured? Available at http://www.is.cityu.edu.hk/Research/WorkingPapers/paper/9401.pdf Accessed on July 14, 2006

US Bureau of Economic Analysis 2000. National Income and Product Accounts Table. Available at http://www.bea.gov/national/index.htm\#fixed 